\title{
Article
}

\section{Honeycomb-structured solid acid catalysts fabricated via the swelling-induced self-assembly of acidic poly(ionic liquid)s for highly efficient hydrolysis reactions}

\author{
Bihua Chen a, Tong Ding a, Xi Deng a , Xin Wang a, Dawei Zhang a,b, Sanguan Ma a, Yongya Zhanga, \\ Bing $\mathrm{Ni}^{\mathrm{c}}$, Guohua Gao ${ }^{\mathrm{a}, *}$ \\ a Shanghai Key Laboratory of Green Chemistry and Chemical Processes, School of Chemistry and Molecular Engineering, East China Normal University, \\ Shanghai 200062, China \\ b Department of Chemistry, University of Cambridge, Cambridge CB2 1EW, U.K. \\ c School of Life Sciences, East China Normal University, Shanghai 200241, China
}

\section{A R T I C L E I N F}

\section{Article history:}

Received 29 March 2020

Accepted 8 May 2020

Published 5 February 2021

\section{Keywords:}

Heterogeneous acid catalyst

Acidic poly(ionic liquid)

Swelling

3D honeycomb structure

Enrichment

Hydrolysis

Hydration

\begin{abstract}
A B S T R A C T
The development of heterogeneous acid catalysts with higher activity than homogeneous acid catalysts is critical and still challenging. In this study, acidic poly(ionic liquid)s with swelling ability (SAPILs) were designed and synthesized via the free radical copolymerization of ionic liquid monomers, sodium $p$-styrenesulfonate, and crosslinkers, followed by acidification. The ${ }^{31} \mathrm{P}$ nuclear magnetic resonance chemical shifts of adsorbed trimethylphosphine oxide indicated that the synthesized SAPILs presented moderate and single acid strength. The thermogravimetric analysis results in the temperature range of $300-345{ }^{\circ} \mathrm{C}$ revealed that the synthesized SAPILs were more stable than the commercial resin Amberlite IR-120(H) $\left(245^{\circ} \mathrm{C}\right)$. Cryogenic scanning electron microscopy testing demonstrated that SAPILs presented unique three-dimensional (3D) honeycomb structure in water, which was ascribed to the swelling-induced self-assembly of the molecules. Moreover, we used SAPILs with micron-sized honeycomb structure in water as catalysts for the hydrolysis of cyclohexyl acetate to cyclohexanol, and determined that their catalytic activity was much higher than that of homogeneous acid catalysts. The equilibrium concentrations of all reaction components inside and outside the synthesized SAPILs were quantitatively analyzed using a series of simulated reaction mixtures. Depending on the reaction mixture, the concentration of cyclohexyl acetate inside SAPIL-1 was 7.5-23.3 times higher than that outside of it, which suggested the high enrichment ability of SAPILs for cyclohexyl acetate. The excellent catalytic performance of SAPILs was attributed to their 3D honeycomb structure in water and high enrichment ability for cyclohexyl acetate, which opened up new avenues for designing highly efficient heterogeneous acid catalysts that could eventually replace conventional homogeneous acid catalysts.
\end{abstract}

(C) 2021, Dalian Institute of Chemical Physics, Chinese Academy of Sciences. Published by Elsevier B.V. All rights reserved.

\section{Introduction}

Acid catalysis is an important reaction that has been widely used for the production of petrochemicals, conversion of bio-

\footnotetext{
* Corresponding author. Tel/Fax: +86-21-62233323; E-mail: ghgao@chem.ecnu.edu.cn

This work was supported by the National Natural Science Foundation of China (21773068, 21573072, 21811530273), the National Key Research and Development Program of China (2017YFA0403102) and Shanghai Leading Academic Discipline Project (B409).

DOI: 10.1016/S1872-2067(20)63658-0 | http://www.sciencedirect.com/science/journal/18722067 | Chin. J. Catal., Vol. 42, No. 2, February 2021
} 
mass, synthesis of fine chemicals, and other industrial processes [1-4]. Conventional homogeneous acid catalysts, such as $\mathrm{H}_{2} \mathrm{SO}_{4}$ and $\mathrm{HF}$, have been used extensively for many acid-catalyzed chemical processes owing to their high acid strength, uniform distribution of acid sites, and excellent catalytic activity [1,5-7]. However, several shortcomings could be associated with their use, such as significant environmental pollution, equipment corrosion, and high energy consumption $[8,9]$. To address these problems, much attention has been paid to the replacement of conventional homogeneous acid catalysts with heterogeneous ones $[4,10]$. To date, various heterogeneous acid catalysts, such as zeolites, metal oxides, and ion exchange resins, have been successfully used for many chemical industrial processes $[1,11,12]$. However, heterogeneous acid catalysts still present drawbacks, such as high mass transfer resistance, facile leaching of active sites, low activity and selectivity, and poor stability $[4,12,13]$.

Acidic poly(ionic liquid)s (APILs) [14-16], which combine the characteristics of acids, polymers and ionic liquids (ILs), are an emerging subclass of acidic ILs that have been successfully used as heterogeneous acid catalysts [17-25] owing to their advantages, including their structural designability, organic frameworks, controllable acid strength, and adjustable acid concentration [14]. However, similar to most heterogeneous acid catalysts, APILs generally present lower catalytic activity than homogeneous acid catalysts because of the lower degree of exposure of the acid sites to the reactants [17]. Many efforts have been made to increase the dispersibility of acid sites, and consequently, to improve their catalytic activity, and an effective approach was the synthesis of porous APILs [19-22]. The presence of pores could substantially accelerate the mass transfer and increase the accessibility of reactants to the acid sites. Another useful method involved the preparation of APIL microspheres and nanoparticles [23-25]. These micro- and nanostructures could bring highly dispersed acid sites to the reactants. Despite the significant advances in the synthesis of highly efficient APIL catalysts, their activity has been typically lower than that of homogeneous acid catalysts. Consequently, the development of APILs with higher catalytic activity than homogeneous acid catalysts is still a great challenge.

Recently, we developed a series of carboxylate-based poly(ionic liquid)s (PILs) with high swelling abilities in ethylene carbonate [26-28]. These PILs were used as efficient catalysts for the transformation of ethylene carbonate, and their activity was comparable with that of the corresponding homogeneous ILs. The high catalytic activity was attributed to the sufficient exposure of the active sites to the reactants, which was attributed to the swelling ability of the PILs in ethylene carbonate. These studies suggested that the swelling ability of PILs was helpful for enhancing their catalytic activity. Consequently, APILs with swelling ability in reactants could be highly efficient heterogeneous acid catalysts that could be used for many acid-catalyzed reactions, such as hydrolysis, hydration, esterification, and alkylation.

Cyclohexanol is a very important intermediate for the synthesis of adipic acid, hexamethylenediamine, cyclohexanone, and $\varepsilon$-caprolactam, and has been widely used in the coatings, surfactants, and textile industries [29]. The efficient production of cyclohexanol has attracted the attention of many researchers. Three main cyclohexanol synthesis methods have been developed, namely phenol hydrogenation, cyclohexane oxidation, and cyclohexene hydration [29,30]. Phenol hydrogenation is disadvantageous owing to the high price of phenol, the feedstock. The main problems associated with the cyclohexane oxidation reaction are its low conversion and selectivity. Therefore, the hydration of cyclohexene has been considered to be the most promising cyclohexanol synthesis method owing to its high atom economy and selectivity advantages. Many heterogeneous acid catalysts, such as zeolites and sulfonic resins, have been developed for the hydration of cyclohexene; however, their catalytic activity has been typically lower than that of homogeneous acid catalysts [30-33].

In this study, acidic poly(ionic liquid)s with swelling ability (SAPILs) in water, which presented moderate and single acid strength, adjustable acid concentration, and good stability, were successfully prepared via copolymerization and acidification. The swelling of SAPILs in water spontaneously promoted their self-organization, and led to the formation of micron-sized three-dimensional (3D) honeycomb structures. The prepared SAPILs presented much better catalytic performance for the hydrolysis of cyclohexyl carboxylate and direct hydration of cyclohexene to cyclohexanol than homogeneous acid catalysts did. The excellent catalytic performance of SAPILs was analyzed in depth by studying the effect of the enrichment ability and honeycomb structure of the SAPILs in swollen state.

\section{Experimental}

\subsection{Chemicals and materials}

$\mathrm{N}_{2}$ ( $>99.9 \%$ purity) was supplied by Shanghai Tomoe Gases Co., Ltd. Cyclohexene (99\% purity), 1-vinylimidazole (99\% purity), 1,3-propane sultone (99\% purity), 1,4-butane sultone (99\% purity), and $p$-toluenesulfonic acid monohydrate ( $p$ - $\mathrm{TsOH} \cdot \mathrm{H}_{2} \mathrm{O}, 99 \%$ purity) were purchased from J \& K. Sodium $p$-styrenesulfonate (NaSS, $>93 \%$ purity) was obtained from TCI. Cyclohexyl propionate (98\% purity), cyclohexyl butyrate (98\% purity), and phenyl acetate (98\% purity) were supplied by TCI. Chemically pure 2,2'-azobisisobutyronitrile (AIBN), cyclohexanol, acetic acid, ethylene oxide (EO), and ethylene glycol (EG) were purchased from Sinopharm. Analytical grade $\mathrm{H}_{2} \mathrm{SO}_{4}$ and phenol were obtained from Sinopharm. Cyclohexyl acetate (99\% purity) was supplied by Ourchem. Reagent grade Amberlite IR-120(Na) was purchased from Adamas Reagent Co., Ltd. Zeolite H-ZSM-5 (Si/Al ratio of 25) was obtained from the Catalyst Plant of Nankai University. Trimethylphosphine oxide (TMPO, 97\% purity) was purchased from Macklin. In addition, we synthesized 1,8-triethylene glycoldiyl-3,3'-divinylimidazolium bromide ([EG3 $\left.\left(\mathrm{VIm}_{2}\right] \mathrm{Br}_{2}\right)$, 1,8-dioctyl-3,3'- divinylimidazolium bromide ([O(VIm) $\left.\left.)_{2}\right] \mathrm{Br}_{2}\right)$, and 1-vinyl-3- (3-sulfopropyl)imidazolium hydrogen sulfate ([VSIm] $\mathrm{HSO}_{4}$ ), an acidic IL (see Supporting Information). Deionized water and other chemicals and materials were purchased from local suppliers and were used as received, without 
further purification.

\subsection{Characterization}

Both ${ }^{1} \mathrm{H}$ and ${ }^{13} \mathrm{C}$ nuclear magnetic resonance (NMR) spectra were recorded at the frequencies of 400 and $100 \mathrm{MHz}$ using an Ascend 400 (Bruker Daltonics Inc., USA) spectrometer with tetramethylsilane as the internal standard. All ${ }^{13} \mathrm{C}$ solid-state magic angle spinning (MAS) NMR spectra were acquired using a VNMRS-400 WB (VARIAN, USA) spectrometer under one pulse conditions, at the frequency of $100 \mathrm{MHz}$, spinning rate of $9.0 \mathrm{kHz}$, and recycling delay of $4 \mathrm{~s}$. Fourier-transform infrared (FT-IR) spectra were obtained using a Nexus Spectrum 670 FT-IR spectrometer (Thermo Nicolet, USA) using $\mathrm{KBr}$ pellets. X-ray photoelectron spectroscopy (XPS) experiments were performed using an AXIS SUPRA (Shimadzu/Kratos, UK) photoelectron spectrometer with $\mathrm{Al} K_{\alpha}$ radiation at $\theta=90^{\circ}$, and its binding energies were calibrated using the $\mathrm{C} 1 s$ peak at 284.8 $\mathrm{eV}$. Thermogravimetric analysis (TGA) was performed using a STA449 F3 Jupiter (Netzsch, Germany) instrument at the heating rate of $10{ }^{\circ} \mathrm{C} / \mathrm{min}$ in the temperature range of $25-800{ }^{\circ} \mathrm{C}$ under a stream of $\mathrm{N}_{2}$. The initial mass of each sample was 5-8 mg. $\mathrm{N}_{2}$ adsorption-desorption isotherms were obtained at $-196{ }^{\circ} \mathrm{C}$ using a BELSORP-Max (MicrotracBEL, Japan) volumetric adsorption equipment. Prior to each measurement, the samples were degassed at $150{ }^{\circ} \mathrm{C}$ under vacuum for $6 \mathrm{~h}$. The Brunauer-Emmett-Teller (BET) specific surface areas were calculated utilizing the BET equation using five relative pressure points in the range of 0.05-0.30. X-ray powder diffraction (XRD) analysis was performed using an Ultima IV (Rigaku, Japan) diffractometer with $\mathrm{Cu} K_{\alpha}$ radiation. Scanning electron microscopy (SEM) measurements were performed using a G2 Pro Desktop (Phenom, Netherlands) instrument. The internal morphologies of the swollen samples were examined using an S-4800 (Hitachi, Japan) cryogenic scanning electron microscopy apparatus equipped with an Alto-2100 (Gatan, UK) refrigerating system. After sufficient swelling for $24 \mathrm{~h}$, the swollen samples were separated, frozen at $-160{ }^{\circ} \mathrm{C}$, and placed inside the sample holder. The top section of each frozen samples was cut using a scraper. Then the samples were sublimated at -95 ${ }^{\circ} \mathrm{C}$ and imaged at $1.0 \mathrm{kV}$. The contact angles (CAs) of the samples were obtained on a Theta (Biolin Scientific, Sweden) optical contact angle measuring instrument. Before testing, the samples were pressed into tablets using a 769YP-24B (Tianjin Keqi High \& New Technology Corporation, China) tablet machine. The acid concentrations of the samples were determined via acid-base titration using standard $\mathrm{NaOH}$ solution and phenolphthalein as the titrant and indicator, respectively [9,10,25]. The acid strengths of the samples were evaluated using the 31P-TMPO NMR approach [34]. Before analysis, the samples were treated as follows. Powder samples were added to sealed glass flasks with stopcocks and were degassed at $100{ }^{\circ} \mathrm{C}$ for 24 $\mathrm{h}$ under vacuum to remove the adsorbed water. Then, an anhydrous $\mathrm{CH}_{2} \mathrm{Cl}_{2}$ (distillated in $\mathrm{CaH}_{2}$ ) solution that contained the TMPO probe molecule was added to the flask, which was placed inside a glovebox. To ensure the sufficient adsorption of TMPO, the loaded samples were stirred for $24 \mathrm{~h}$ at room tem- perature. $\mathrm{CH}_{2} \mathrm{Cl}_{2}$ was evacuated at $60^{\circ} \mathrm{C}$ for $3 \mathrm{~h}$. Then, the samples that adsorbed TMPO were packed into a $\mathrm{ZrO}_{2}$ MAS rotor inside a glovebox, for further analysis. The ${ }^{31} \mathrm{P}$ solid-state MAS NMR spectra of the samples were recorded using a VNMRS-400 WB (VARIAN, USA) spectrometer.

\subsection{Preparation of SAPILs}

\subsubsection{Synthesis of IL monomers}

First, 1,3-propane sultone (12.21 g, $0.1 \mathrm{~mol}$ ) was dissolved in $20 \mathrm{~mL}$ THF in a $100 \mathrm{~mL}$ round-bottom flask. Then, a solution of 1-vinylimidazole $(9.41 \mathrm{~g}, 0.1 \mathrm{~mol})$ in $5 \mathrm{~mL}$ THF was slowly added to the flask. The mixture was stirred at room temperature for $24 \mathrm{~h}$. The obtained white solid was washed with diethyl ether and dried under vacuum at $60{ }^{\circ} \mathrm{C}$ for $12 \mathrm{~h}$. The desired product, 1-vinyl-3-(3-sulfopropyl)imidazolium (VSIm), was obtained at the yield of approximately $80 \%$ (17.25 g), and was structurally characterized using NMR spectroscopy. ${ }^{1} \mathrm{H}$ NMR (400 MHz, DMSO-d 6 , TMS) $\delta: 9.48(\mathrm{~s}, 1 \mathrm{H}), 8.19(\mathrm{~s}, 1 \mathrm{H}), 7.94(\mathrm{~s}$, 1H), 7.29 (dd, $J=15.6,8.8 \mathrm{~Hz}, 1 \mathrm{H}$ ), 5.95 (dd, $J=15.6,2.4 \mathrm{~Hz}$, 1H), 5.40 (dd, $J=8.8,2.4 \mathrm{~Hz}, 1 \mathrm{H}), 4.34(\mathrm{t}, J=7.0 \mathrm{~Hz}, 2 \mathrm{H}), 2.45(\mathrm{t}$, $J=7.0 \mathrm{~Hz}, 2 \mathrm{H}), 2.17-2.09(\mathrm{~m}, 2 \mathrm{H}) ;{ }^{13} \mathrm{C}$ NMR $(100 \mathrm{MHz}$, DMSO-d6, TMS) $\delta: 135.68,128.96,123.33,119.08,108.46$, 48.23, 47.38, 25.92.

Similarly, the IL monomer 1-vinyl-3-(4-sulfobutyl)imidazolium (VSbIm) was synthesized via the reaction of 1-vinylimidazole with 1,4-butane sultone, and was structurally characterized using NMR spectroscopy. ${ }^{1} \mathrm{H}$ NMR (400 MHz, $\left.\mathrm{D}_{2} \mathrm{O}, \mathrm{TMS}\right) \delta: 9.08(\mathrm{~s}, 1 \mathrm{H}), 7.79(\mathrm{~s}, 1 \mathrm{H}), 7.61(\mathrm{~s}, 1 \mathrm{H}), 7.14(\mathrm{dd}, J=$ 15.6, $8.8 \mathrm{~Hz}, 1 \mathrm{H}$ ), 5.80 (dd, $J=15.6,2.8 \mathrm{~Hz}, 1 \mathrm{H}), 5.43$ (dd, $J=8.8$, $2.8 \mathrm{~Hz}, 1 \mathrm{H}), 4.30(\mathrm{t}, J=7.0 \mathrm{~Hz}, 2 \mathrm{H}), 2.96(\mathrm{t}, J=7.6 \mathrm{~Hz}, 2 \mathrm{H})$, 2.10-2.02 (m, 2H), 1.81-1.73 (m, 2H); ${ }^{13} \mathrm{C}$ NMR (100 MHz, $\mathrm{D}_{2} \mathrm{O}$, TMS) $\delta: 134.52,128.18,122.72,119.51,109.28,49.98,49.23$, 27.90, 20.87.

\subsubsection{Synthesis of SAPILS}

SAPILs were synthesized using a two-step procedure that consisted of free radical copolymerization and subsequent acidification. The typical synthesis consisted of the following steps. First, VSIm (1.05 g, $4.875 \mathrm{mmol})$, NaSS (1.00 g, 4.875 $\mathrm{mmol})$, the $\left[\mathrm{EG}_{3}(\mathrm{VIm})_{2}\right] \mathrm{Br}_{2}(0.12 \mathrm{~g}, 0.25 \mathrm{mmol})$ crosslinker, and $5 \mathrm{~mL} \mathrm{H}_{2} \mathrm{O}$ were added to a $50 \mathrm{~mL}$ two-necked round-bottom flask equipped with a magnetic stirrer. After stirring for $0.5 \mathrm{~h}$ at room temperature, the mixture was gradually heated to $80{ }^{\circ} \mathrm{C}$. Then, AIBN (0.11 g, $5 \mathrm{wt} \%$ ), the initiator, was added to the flask, and the mixture was stirred at $80{ }^{\circ} \mathrm{C}$ for $24 \mathrm{~h}$ under $\mathrm{N}_{2}$ atmosphere. After copolymerization, the SAPIL precursor was cooled to room temperature, washed with excess methanol and water several times, and dried under vacuum at $60{ }^{\circ} \mathrm{C}$ for $12 \mathrm{~h}$. Then, the obtained SAPIL precursor and $100 \mathrm{~mL}$ of $1 \mathrm{M} \mathrm{H}_{2} \mathrm{SO}_{4}$ solution were added to a $250 \mathrm{~mL}$ beaker equipped with a magnetic stirrer, and the mixture was stirred for $24 \mathrm{~h}$ at room temperature. The formed SAPIL was washed with excess water several times until the $\mathrm{pH}$ of the washing liquid was neutral, and dried under vacuum at $60{ }^{\circ} \mathrm{C}$ for $12 \mathrm{~h}$. A canary yellow SAPIL was obtained at the total yield of approximately $84 \%$. Other SAPILs featuring different types and contents of cross- 
linkers and different IL monomer species were prepared using similar processes.

\subsection{Measurement of the swelling ratio}

During a typical measurement, dried SAPIL (50 mg) was added to a sealed bottle that contained $10 \mathrm{~mL}$ solvent. The swelling process was allowed to reach equilibrium for $24 \mathrm{~h}$ at room temperature. Then the swollen SAPIL was removed from the bottle, and the solvent on its surface was removed by wiping it with absorbent paper. The mass of the swollen SAPIL was measured immediately afterward, and the swelling ratio (Q) of the SAPIL was calculated using the following equation:

$$
\mathrm{Q}=\left(m_{\text {swollen }}-m_{\text {dried }}\right) / m_{\text {dried }}(\mathrm{g} / \mathrm{g})
$$

where $m_{\text {swollen }}$ and $m_{\text {dried }}$ represent the masses of the swollen and dried SAPIL, respectively.

\subsection{Catalytic tests}

\subsubsection{Hydrolysis of esters}

The hydrolysis of cyclohexyl acetate was carried out in a 50 mL stainless-steel Teflon-lined YZPR-50 (Yanzheng Experiment Instrument, China) autoclave equipped with a magnetic stirrer and an automatic temperature control system. During a typical run, cyclohexyl acetate (1.42 g, $10 \mathrm{mmol})$, deionized water ( $4.50 \mathrm{~g}, 250 \mathrm{mmol}$ ), and SAPIL ( $4 \mathrm{~mol} \%$ catalyst relative to the cyclohexyl acetate, equivalent to $0.4 \mathrm{mmol} \mathrm{H}^{+}$) were added to the autoclave. The autoclave was pressurized with $\mathrm{N}_{2}(1 \mathrm{bar})$ and heated to $100{ }^{\circ} \mathrm{C}$. After stirring for $7 \mathrm{~h}$, the autoclave was cooled to room temperature in an ice-water bath, and then it was slowly vented. After the SAPIL catalyst was separated, the reaction mixture was analyzed using a gas chromatography (GC; GC-2014, Shimadzu, Japan) instrument with a DM-1701 $(30 \mathrm{~m} \times 0.53 \mathrm{~mm} \times 1.0 \mu \mathrm{m})$ capillary column and flame ionization detector; biphenyl was used as the internal standard. The hydrolysis of other esters was performed following the same procedure.

The SAPIL catalyst was recovered via deswelling with acetone, and then it was separated and washed with $5 \mathrm{~mL}$ acetone three times. The recovered SAPIL was dried under vacuum at $60^{\circ} \mathrm{C}$ for $12 \mathrm{~h}$, and then it was reused for the next run.

\subsubsection{Direct hydration of cyclohexene}

Typically, cyclohexene (1.64 g, $20 \mathrm{mmol})$, deionized water ( $3.60 \mathrm{~g}, 200 \mathrm{mmol}$ ), and SAPIL ( $1 \mathrm{~mol} \%$ catalyst relative to the cyclohexene, equivalent to $0.2 \mathrm{mmol} \mathrm{H}^{+}$) were added to the autoclave. The autoclave was pressurized with $\mathrm{N}_{2}(0.5 \mathrm{MPa})$ and heated to $130{ }^{\circ} \mathrm{C}$. After the reaction ended, the autoclave was cooled to room temperature in an ice-water bath, and then it was slowly vented. After the separation of the SAPIL catalyst, the reaction mixture was analyzed via GC using biphenyl as the internal standard.

\subsubsection{Hydration of EO}

Typically, EO (2.20 g, $50 \mathrm{mmol})$, deionized water $(9.01 \mathrm{~g}$, $500 \mathrm{mmol})$ and SAPIL $(0.12 \mathrm{~mol} \%$ catalyst relative to the EO, equivalent to $0.06 \mathrm{mmol} \mathrm{H}^{+}$) were added to the autoclave. The autoclave was pressurized with $\mathrm{N}_{2}(1.0 \mathrm{MPa})$ and heated to 100 ${ }^{\circ} \mathrm{C}$. After stirring for $0.5 \mathrm{~h}$, the autoclave was cooled to room temperature in an ice-water bath, and then it was slowly vented. After the SAPIL catalyst was separated, the reaction mixture was analyzed via GC using $n$-dodecane as the internal standard.

\subsection{Quantitative analysis of the cyclohexyl acetate enrichment ability of SAPILs in swollen state}

Typically, a simulated reaction mixture of cyclohexyl acetate ( $0.71 \mathrm{~g}, 5 \mathrm{mmol})$, water ( $4.41 \mathrm{~g}, 245 \mathrm{mmol})$, cyclohexanol $(0.50$ g, $5 \mathrm{mmol})$, and acetic acid ( $0.30 \mathrm{~g}, 5 \mathrm{mmol})$, which was the equivalent of the reaction mixture used for the $50 \%$ conversion of cyclohexyl acetate via hydrolysis, was prepared and named Mixture-50\% (here 50\% represents the conversion of cyclohexyl acetate in the simulated reaction mixture). Mixture-50\% and SAPIL-1 ( $0.102 \mathrm{~g}$, equivalent to $\left.0.2 \mathrm{mmol} \mathrm{H}^{+}\right)$were added to a $25 \mathrm{~mL}$ sealed bottle equipped with a magnetic stirrer. After stirring for $12 \mathrm{~h}$ at room temperature, the mixture was allowed to sit for $4 \mathrm{~h}$, and then, the aqueous phase, which contained swollen SAPIL-1, was separated. The swollen SAPIL-1 was removed from the aqueous phase and was deswelled with acetone. The acetone solution was analyzed via GC using biphenyl as the internal standard, and the concentrations of cyclohexyl acetate, cyclohexanol, and acetic acid inside SAPIL-1 were calculated. In addition, the concentrations of all components of the aqueous phase (outside SAPIL-1) were measured using a similar method. The enrichment ability of SAPIL-1 was determined by comparing the concentrations of all components inside and outside SAPIL-1. The quantitative analysis of the enrichment ability of SAPIL-1 in Mixture-10\%, 30\%, 70\% and 90\% (which corresponded to the reaction mixtures used to achieve the hydrolysis conversion of cyclohexyl acetate of $10 \%, 30 \%, 70 \%$, and $90 \%$, respectively) was performed using the same procedure.

For comparison, the concentrations of each component in the aqueous phases of Mixture-10\%, 30\%, 50\%, 70\%, and 90\% over the homogeneous acid catalyst $p$ - TsOH $(0.102$ g, equivalent to $0.2 \mathrm{mmol} \mathrm{H}^{+}$) were also obtained.

\section{Results and discussion}

\subsection{Synthesis and characterization of SAPILS}

The SAPILs were synthesized using a two-step procedure (Scheme 1). First, SAPIL precursors were prepared via the free radical copolymerization of the IL monomers (VSIm or VSbIm), $\mathrm{NaSS}$, and crosslinkers ([EG3 $\left.(\mathrm{VIm})_{2}\right] \mathrm{Br}_{2}$ or $\left.\left[\mathrm{O}\left(\mathrm{VIm}_{2}\right)_{2}\right] \mathrm{Br}_{2}\right)$ in the presence of AIBN as the initiator at $80^{\circ} \mathrm{C}$ for $24 \mathrm{~h}$ in $\mathrm{H}_{2} \mathrm{O}$ under $\mathrm{N}_{2}$ atmosphere. Then, the target SAPILs were obtained via the acidification of the SAPIL precursors in $1 \mathrm{M} \mathrm{H}_{2} \mathrm{SO}_{4}$ solution. Six SAPIL samples were successfully synthesized, and the synthesis conditions for each sample are listed in Table 1.

The structure of the synthesized SAPILs was characterized using NMR spectroscopy. The ${ }^{13} \mathrm{C}$ solid-state MAS NMR spectra of the SAPILs and ${ }^{13} \mathrm{C}$ NMR spectra of the corresponding monomers, namely VSIm and NaSS, are illustrated in Fig. 1. The 


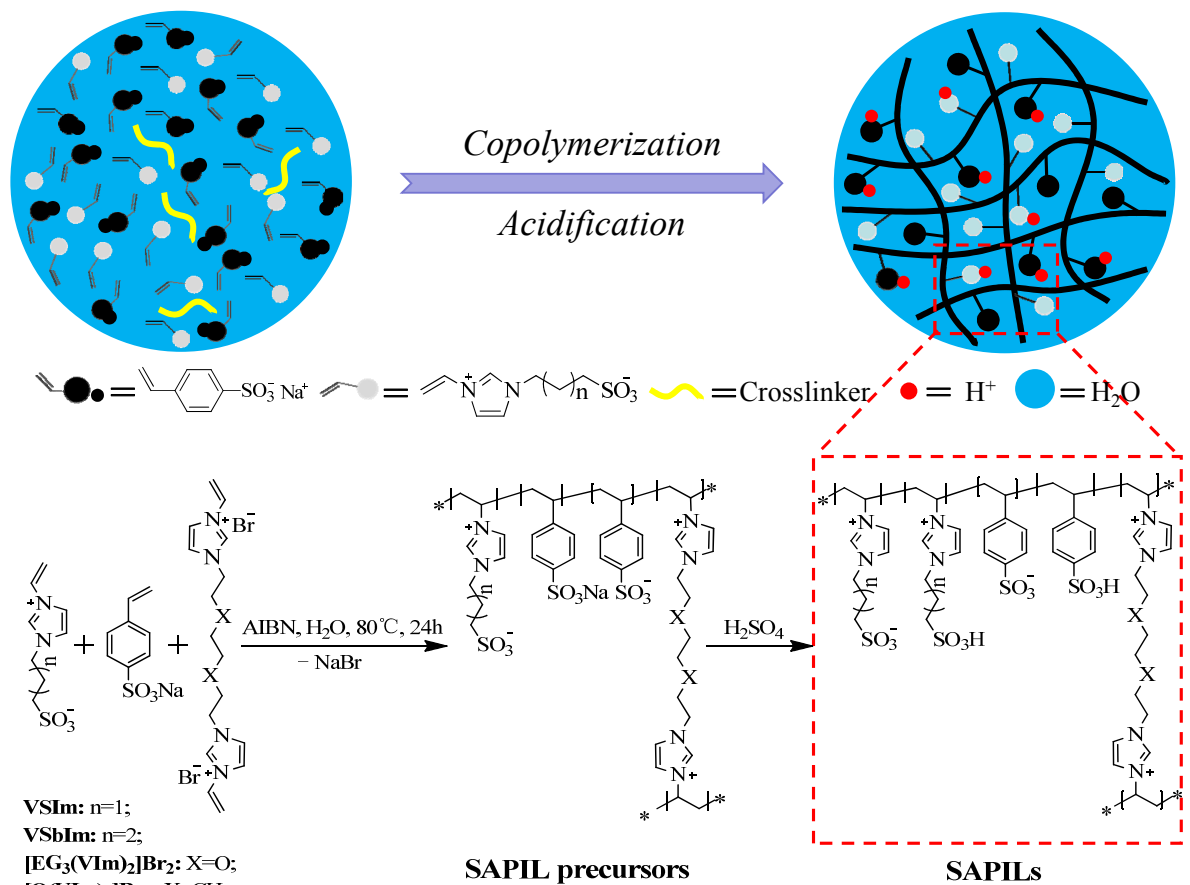

Scheme 1. Schematic illustration of the synthesis process of acidic poly(ionic liquid)s with swelling ability (SAPILs). Here AIBN, VSIm, VSbIm, $\left[\mathrm{EG}_{3}(\mathrm{Vim})_{2}\right] \mathrm{Br}_{2}$, and $\left[\mathrm{O}(\mathrm{Vim})_{2}\right] \mathrm{Br}_{2}$ denote 2,2'-azobisisobutyronitrile, 1-vinyl-3-(3-sulfopropyl)imidazolium, 1-vinyl-3-(4-sulfobutyl)imidazolium, 1,8-triethylene glycoldiyl-3,3'-divinylimidazolium bromide, and 1,8-dioctyl-3,3'-divinylimidazolium bromide, respectively.

signals at $\delta \approx 115$ and 108 , which belonged to the vinyl groups of NaSS and VSIm, respectively, were not observed in the spectra of SAPILs, which indicated the complete copolymerization of the monomers. The new signals at $\delta \approx 57$ and 40 were assigned to the $\mathrm{C}$ atoms of the newly formed polymer chains [26]. The signals at $\delta \approx 68$ in the spectra of SAPIL-1-4 belonged to the $\left[\mathrm{EG}_{3}(\mathrm{VIm})_{2}\right] \mathrm{Br}_{2}$ crosslinker (Fig. S1(a)), and the intensity of the signals increased as the molar fraction of [ $\left.\mathrm{EG}_{3}(\mathrm{VIm})_{2}\right] \mathrm{Br}_{2}$ in the SAPILs increased.

The successful copolymerization of the monomers was confirmed using the FT-IR spectra of the SAPILs (Figs. S2-S4). The band at approximately $1630 \mathrm{~cm}^{-1}$ which belonged to the stretching vibrations of the $\mathrm{C}=\mathrm{C}$ bonds of the vinyl groups of

\section{Table 1}

Conditions for the synthesis of acidic poly(ionic liquid)s with swelling ability (SAPILs) and their swelling ratios (Q) in water. ${ }^{c}$

\begin{tabular}{lcccc}
\hline Sample & $\begin{array}{c}\mathrm{IL}^{\mathrm{a}} \\
(\mathrm{mmol})\end{array}$ & $\begin{array}{c}\mathrm{NaSS} \\
(\mathrm{mmol})\end{array}$ & $\begin{array}{c}\text { Crosslinker } \\
(\mathrm{mmol})\end{array}$ & $\begin{array}{c}\mathrm{Q} \\
(\mathrm{g} / \mathrm{g})\end{array}$ \\
\hline SAPIL-1 & 4.875 & 4.875 & 0.25 & 24.5 \\
SAPIL-2 & 4.750 & 4.750 & 0.50 & 14.3 \\
SAPIL-3 & 4.500 & 4.500 & 1.00 & 6.5 \\
SAPIL-4 & 4.000 & 4.000 & 2.00 & 1.6 \\
SAPIL-5 $^{\mathrm{d}}$ & 4.875 & 4.875 & 0.25 & 14.4 \\
SAPIL-6 $^{\mathrm{e}}$ & 4.875 & 4.875 & 0.25 & 27.4 \\
\hline
\end{tabular}

a Ionic liquid. b Sodium $p$-styrenesulfonate. c SAPIL-1-4: 1-vinyl-3(3-sulfopropyl)imidazolium (VSIm) and 1,8-triethylene glycoldiyl-3,3'-divinylimidazolium bromide $\left(\left[\mathrm{EG}_{3}\left(\mathrm{VIm}_{2}\right] \mathrm{Br}_{2}\right)\right.$ were used as the IL and crosslinker, respectively. ${ }^{d}$ SAPIL-5: VSIm and 1,8-dioctyl$3,3^{\prime}$-divinylimidazolium bromide $\left(\left[\mathrm{O}(\mathrm{VIm})_{2}\right] \mathrm{Br}_{2}\right)$ were used as the IL and crosslinker, respectively; eSAPIL-6: 1-vinyl-3-(4-sulfobutyl)imidazolium (VSbIm) and $\left[\mathrm{EG}_{3}(\mathrm{VIm})_{2}\right] \mathrm{Br}_{2}$ were used as the IL and crosslinker, respectively.
NaSS and VSIm was not observed in the FT-IR spectrum of SAPIL-1 (Fig. S2). The bands at approximately 1644, 1569, and $1553 \mathrm{~cm}^{-1}$ were attributed to the stretching vibrations of the $\mathrm{C}=\mathrm{N}$ and $\mathrm{C}=\mathrm{C}$ bonds of the imidazolium rings [25]. The bands at approximately 1605, 1569, and $1498 \mathrm{~cm}^{-1}$ were associated with the stretching vibrations of the benzene rings. The band at approximately $837 \mathrm{~cm}^{-1}$ was assigned to the out-of-plane bending vibration of the $p$-disubstituted benzene rings. The band at approximately $1037 \mathrm{~cm}^{-1}$ was associated with the presence of the C-S moieties on VSIm and NaSS [10]. The bands

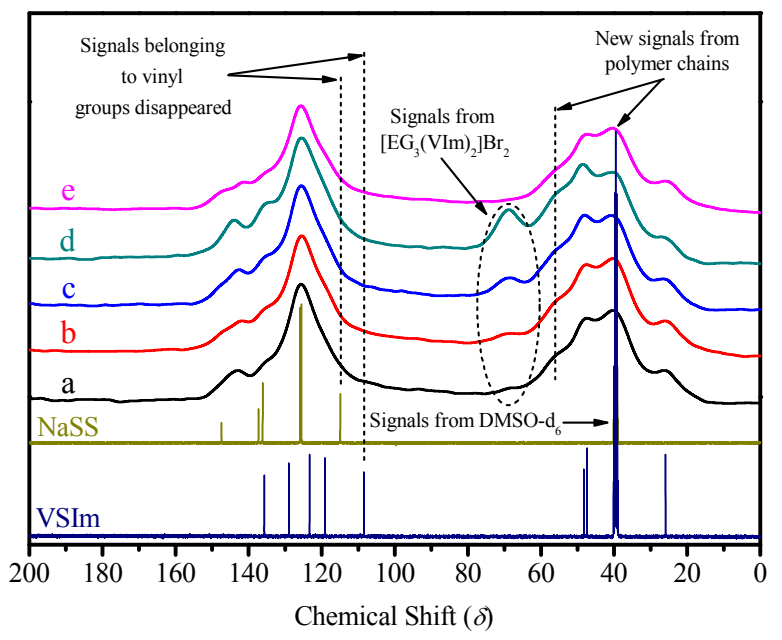

Fig. 1. ${ }^{13} \mathrm{C}$ solid-state magic angle spin NMR spectra of SAPIL-1 (a), SAPIL-2 (b), SAPIL-3 (c), SAPIL-4 (d), SAPIL-5 (e), and ${ }^{13}$ C NMR spectra of 1-vinyl-3-(3-sulfopropyl)imidazolium (VSIm) and sodium $p$-styrenesulfonate (NaSS) (dimethyl sulfoxide (DMSO)- $\mathrm{d}_{6}$ ). 
at approximately 1175,1126 , and $1006 \mathrm{~cm}^{-1}$ were assigned to the asymmetric and symmetric stretching vibrations of the $S=0$ bonds of the sulfonic groups [10,25]. The FT-IR spectra of SAPIL-2-5, which were synthesized using different types and amounts of crosslinkers were similar (Fig. S3), and no significant differences were observed in the spectra obtained before and after their acidification (Fig. S4).

The XPS spectra of SAPIL-1 and its precursor are depicted in Fig. 2(a), where the characteristic peaks of $\mathrm{C}, \mathrm{N}, \mathrm{O}$, and $\mathrm{S}$ were distinctly observed. The $\mathrm{C} 1 \mathrm{~s}$ peaks at approximately 284.8 and $286.2 \mathrm{eV}$ belonged to the $\mathrm{C}-\mathrm{C}$ and $\mathrm{C}-\mathrm{S}$ bonds (Fig. S5) [10]. The $\mathrm{S} 2 s$ and S $2 p$ peaks at approximately $229.0,165.3$, and $164.3 \mathrm{eV}$ were associated with the $\mathrm{S}=0$ and $\mathrm{S}-0$ bonds (Fig. S6) [10]. These results suggested that VSIm and NaSS were successfully copolymerized, and were in good agreement with the results of the ${ }^{13} \mathrm{C}$ solid-state MAS NMR and FT-IR spectroscopy analyses. Furthermore, the characteristic peak of $\mathrm{Na} 1 s$ at approximately $1071.8 \mathrm{eV}$ was not observed in the spectrum of SAPIL-1 (Fig. 2(a)), which indicated that SAPIL-1 was completely acidified. The XRD pattern of SAPIL-1 (Fig. S7) revealed the amorphous structure of the SAPILs. The BET specific surface areas of the dried SAPILs were negligible, which suggested that the SAPILs presented nonporous structure.

The thermal stabilities of the SAPILs were investigated using TGA. The TGA curves of SAPILs and Amberlite IR-120(H) are illustrated in Fig. 2(b). All SAPIL samples presented mass loss in the temperature range of $25-200{ }^{\circ} \mathrm{C}$, which was assigned to the desorption of water. The mass loss in the temperature range of $300-600{ }^{\circ} \mathrm{C}$ was associated with the decomposition of the sulfonic groups and imidazolium rings and destruction of the polymer networks. As the molar fraction of the crosslinker increased from $2.5 \%$ to $20 \%$, the initial decomposition temperatures of SAPILs increased from 300 to $345{ }^{\circ} \mathrm{C}$, respectively, which could be attributed to the increase in their crosslinking degree [35]. Furthermore, the thermal stability of the SAPILs was much better than that of the commercial resin Amberlite IR-120(H) $\left(245^{\circ} \mathrm{C}\right)$.

The ${ }^{31} \mathrm{P}-\mathrm{TMPO}$ NMR approach has been demonstrated to be an informative tool for the analysis of the acid properties of heterogeneous acid catalysts [36-38]. The ${ }^{31 P}$ solid-state MAS NMR spectrum of TMPO after it interacted with SAPIL-1 presented a single narrow peak at $\delta \approx 62$ (Fig. 2(c)). This peak was attributed to the interactions between TMPO and the Brönsted acid sites of SAPIL-1, and demonstrated the moderate and single acid strength of SAPIL-1 [34,36-38]. Conversely, multiple peaks at $\delta \approx 89,66,60$, and 51 were observed in the spectrum of TMPO after it interacted with H-ZSM-5 (Fig. 2(c)). These results indicated that H-ZSM-5 presented multiple acid strengths, including super $(\delta>85)$, strong $(\delta=70-85)$, medium $(\delta=60-70)$, and weak $(\delta<60)$ acidities [36]. Compared with H-ZSM-5, SAPIL-1 with single acid strength could present potential advantages for improving reaction selectivity.

\subsection{Swelling abilities of SAPILS}

The swelling ability of PILs originates from the electrostatic repulsions between the charges on the polymer chains and osmotic imbalance between the inside and outside areas of the PILs [39]. The $Q$ values were used to evaluate the swelling ability of the PILs. The swelling abilities of the SAPILs in water were measured (Fig. S8) and the results are listed in Table 1. The $Q$ value of SAPIL-1 in water was high (24.5). As the molar fraction of the $\left[\mathrm{EG}_{3}(\mathrm{VIm})_{2}\right] \mathrm{Br}_{2}$ crosslinker increased from $2.5 \%$ (SAPIL-1) to 5\% (SAPIL-2), 10\% (SAPIL-3), and 20\% (SAPIL-4), the swelling ratio significantly decreased from 24.5 to $14.3,6.5$, and 1.6, respectively. This could be attributed to the increase in the crosslinker concentration increasing the crosslinking density, which led to the motion of the polymer chains being restricted, and thus, contributed to the decrease in the swelling ability of the SAPILs [40]. The swelling ability of SAPIL-5, which was synthesized using a more hydrophobic crosslinker $\left(\left[\mathrm{O}(\mathrm{VIm})_{2}\right] \mathrm{Br}_{2}\right)$ than $\left[\mathrm{EG}_{3}(\mathrm{VIm})_{2}\right] \mathrm{Br}_{2}$, in water $(\mathrm{Q}=14.4)$ was lower than that of SAPIL-1. This was attributed to the increase in the hydrophobicity of the crosslinker reducing the interactions between SAPILs and water molecules. The swelling ability of SAPIL-6, which was synthesized using VSbIm, a monomer with longer alkyl chain than VSIm, in water $(Q=27.4)$, was slightly higher than that of SAPIL-1. This could be attributed to the longer alkyl chain weakening the electrostatic attractions between the cations and anions [40,41]. Typically, the swelling ability of SAPILs could be adjusted by changing the types and contents of crosslinkers and the types of IL monomers used to synthesize them. In addition, the swelling abilities of the SAPIL precursors in water were similar with those of the corre-
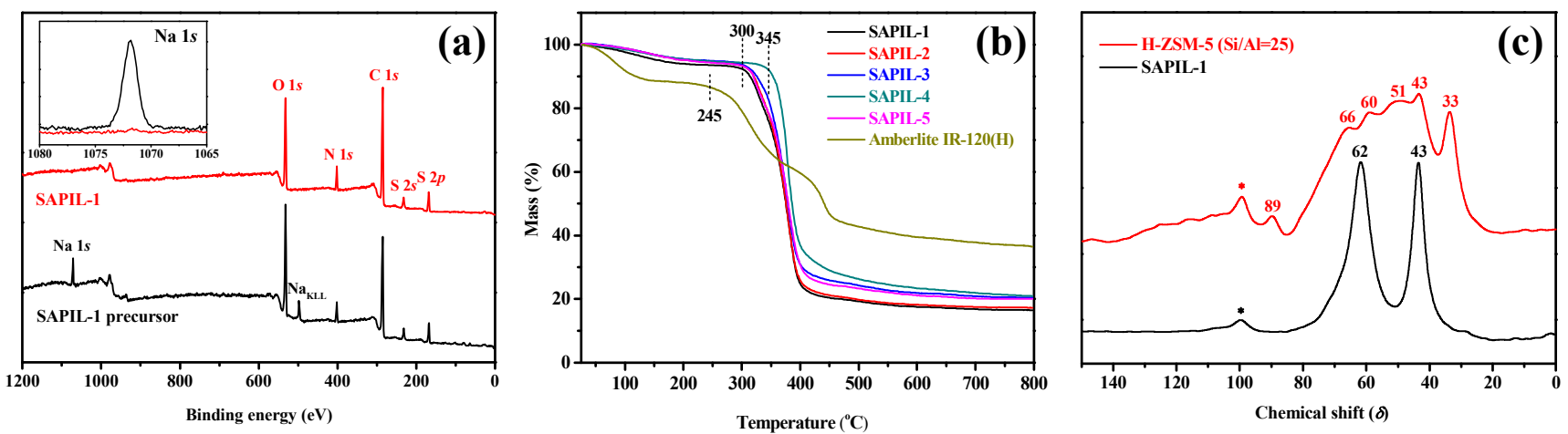

Fig. 2. (a) XPS profiles of SAPIL-1 precursor and SAPIL-1; (b) TG curves of SAPIL-1-5 and Amberlite IR-120(H); (c) ${ }^{31}$ P solid-state magic angle spinning NMR spectra of TMPO chemically adsorbed on SAPIL- 1 and H-ZSM-5 $(\mathrm{Si} / \mathrm{Al}=25)$. The asterisks denote spinning sidebands. The peaks at $\delta \approx 43$ and 33 belonged to the crystalline and physiosorbed TMPO, respectively [36]. 
sponding SAPILs (Table S1), which suggested that acidification did not alter the swelling abilities of SAPILs in water.

The swelling abilities of SAPILs in acidic, salt, and alkaline solutions were also investigated. As illustrated in Table S2, the swelling abilities of SAPIL-1 in $1 \mathrm{M} \mathrm{H}_{2} \mathrm{SO}_{4}, 1 \mathrm{M} \mathrm{NaCl}$, and $1 \mathrm{M}$ $\mathrm{NaOH}$ solutions were low ( $\mathrm{Q}=5.3,6.9$, and 4.3 , respectively), which could be attributed to the high ionic strengths of these solutions [42]. After the SAPIL-1 samples were recovered from the above solutions, their $Q$ values in water were similar to those of a fresh SAPIL-1 sample. In addition, the $Q$ value of SAPIL-1 in water was maintained at $\sim 24$ during five swelling (water)-deswelling (acetone) cycles (Fig. S9). These results suggested that SAPILs presented good chemical stability and reversible swelling-deswelling ability, which were very favorable for catalyst recycling.

\subsection{Swelling-induced self-assembly of SAPILs in water}

The microstructure of the dried SAPILs was investigated using SEM. As displayed in Fig. 3(a), dry SAPIL-1 presented irregular micron-sized particles with nonporous structure, which was in good agreement with the BET specific surface area results. Cryo-SEM was used to study the internal morphologies of SAPILs in swollen state. As illustrated in Fig. 3(b), the swollen SAPIL-1 sample presented unique 3D honeycomb structure, in which the diameters of the channels were approximately 20-30 $\mu \mathrm{m}$ after sublimation for $5 \mathrm{~min}$. The increase in the sublimation time from 5 to 30 min resulted in the partial deformation of the honeycomb structure because more amorphous ice from the water absorbed by SAPIL-1 sublimated (Fig. 3(c)). The magnified image in Fig. 3(d) revealed that the thickness of the swollen SAPIL-1 was approximately $0.6 \mu \mathrm{m}$. Similarly, SAPIL-2, 3, and 5, which presented good swelling ability in water $(\mathrm{Q}=14.3,6.5$, and 14.4 , respectively), also presented unique 3D honeycomb structure in water (Figs. S10(a), (b), and (d), respectively). The diameters of the honeycomb channels gradually decreased from $20-30$ to $3-6 \mu \mathrm{m}$ as $\mathrm{Q}$ decreased from 24.5 to 6.5 , which could be attributed to the increase in the crosslinking degree of the SAPIL samples. Con-
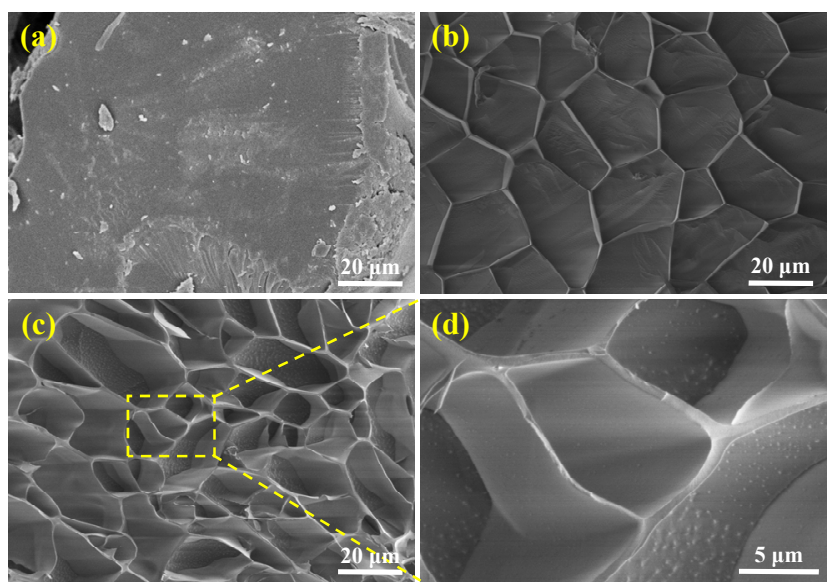

Fig. 3. (a) SEM image of dried SAPIL-1; cryogenic SEM images of fully swollen SAPIL-1 in water sublimated for 5 min (b) and 30 min (c); (d) magnified image of area marked in (c). versely, SAPIL-4, which presented very poor swelling ability in water $(Q=1.6)$ did not exhibit typical 3D honeycomb structure owing to its high crosslinking density and the strong interactions between the polymer chains in its structure (Fig. S10(c)). These results suggested that the good swelling ability in water of the SAPILs played a significant role in the formation of these unique micron-sized 3D honeycomb structures.

The SEM and cryo-SEM images revealed that the structure of the SAPILs spontaneously changed from nonporous to micron-sized 3D honeycomb when they swelled in water. To the best of our knowledge, this is the first report of the swelling-induced self-assembly behavior of PILs to form 3D honeycomb structures. A possible 3D honeycomb structure formation mechanism was proposed, and it is schematically depicted in Fig. 4. When the SAPILs swelled in water (Fig. 4(a)), the interactions between the polymer chains and the osmotic balance between the interior and exterior of the SAPILs were broken, and then, water was absorbed into the SAPILs $[39,43]$. As the number of water molecules inside the SAPILs increased, the entangled polymer chains became gradually stretched (Fig. 4(b)). After the swelling process reached equilibrium, which was driven by the electrostatic interactions between the polymer chains and also the polymer chains and water and hydrogen bonding interactions between the polymers chains and water, the disordered polymer chains self-organized into the most stable 3D honeycomb structures (Fig. 4(c)) $[44,45]$.

\subsection{Catalytic activity of SAPILs for hydrolysis and hydration reactions}

Catalysts with 3D honeycomb structure are expected to be highly efficient, because their unique structure not only provides maximum active sites exposure to the reactants, but also facilitates the accessibility of the reactants to the active sites and shortens their diffusion length [46-50]. Therefore, SAPILs with micron-sized 3D honeycomb structure in water could be highly efficient solid acid catalysts for hydrolysis and hydration reactions.

\subsubsection{Indirect and direct hydration of cyclohexene to cyclohexanol}

Hydrolysis of cyclohexyl acetate to cyclohexanol. The indirect hydration of cyclohexene is a two-step process comprising the esterification of cyclohexene with carboxylic acid to cyclohexyl carboxylate and subsequent hydrolysis of cyclohexyl carboxylate to cyclohexanol [30]. The catalytic activity of SAPILs was evaluated for the hydrolysis of cyclohexyl acetate to cyclohexanol (second step of indirect hydration). Table 2 presents the

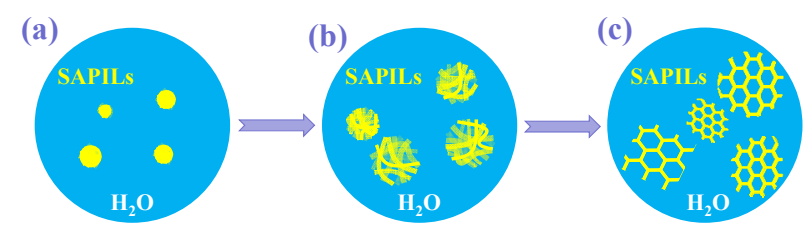

Fig. 4. Schematic illustration of swelling-induced self-assembly process of SAPILs in water. 
Table 2

Hydrolysis of cyclohexyl acetate catalyzed using various catalysts. ${ }^{\mathrm{a}}$

\begin{tabular}{|c|c|c|c|c|c|}
\hline Entry & Catalyst & Type & Acid concentration ${ }^{\mathrm{b}}(\mathrm{mmol} / \mathrm{g})$ & Conversion ${ }^{\mathrm{c}}(\%)$ & Selectivity d (\%) \\
\hline$\overline{1}$ & - & - & - & 1.4 & 100 \\
\hline 2 & SAPIL-1 & Hetero & 1.95 & 81.9 & 98.3 \\
\hline 3 & SAPIL-2 & Hetero & 1.59 & 70.0 & 98.7 \\
\hline 4 & SAPIL-3 & Hetero & 1.12 & 62.9 & 98.9 \\
\hline 5 & SAPIL-5 & Hetero & 1.99 & 72.9 & 98.5 \\
\hline 6 & SAPIL-6 & Hetero & 2.03 & 81.5 & 98.7 \\
\hline 7 & Amberlite IR-120(H) & Hetero & 4.60 & 28.5 & 96.8 \\
\hline $8^{e}$ & H-ZSM-5 & Hetero & 0.86 & 49.3 & 36.3 \\
\hline 9 & {$[\mathrm{VSIm}] \mathrm{HSO}_{4}$} & Homo & 6.23 & 47.1 & 99.2 \\
\hline $10^{\mathrm{f}}$ & $\mathrm{H}_{2} \mathrm{SO}_{4}$ & Homo & 20.39 & 46.2 & 98.9 \\
\hline 11 & $p$-TsOH & Homo & 5.25 & 69.4 & 98.4 \\
\hline
\end{tabular}

a Reaction conditions: cyclohexyl acetate $(10 \mathrm{mmol}), \mathrm{H}_{2} \mathrm{O}(250 \mathrm{mmol})$, catalyst $(0.4 \mathrm{mmol}), 100{ }^{\circ} \mathrm{C}, 7 \mathrm{~h}, 1 \mathrm{bar} \mathrm{N}_{2} .{ }^{\mathrm{b}}$ The acid concentrations of various catalysts were measured via acid-base titration (Table S3). ${ }^{\mathrm{c}}$ Conversion of cyclohexyl acetate. ${ }^{\mathrm{d}}$ Selectivity of cyclohexanol. ${ }^{\mathrm{e}}$ The acid concentration of H-ZSM-5 $(\mathrm{Si} / \mathrm{Al}=25)$ was determined using the temperature programmed desorption of $\mathrm{NH}_{3} .{ }^{\text {f }} \mathrm{The}_{\text {acid }}$ concentration of $\mathrm{H}_{2} \mathrm{SO}_{4}$ was theoretically calculated.

catalytic data for various catalysts for the hydrolysis of cyclohexyl acetate under optimized reaction conditions, which are summarized in Table S4. In the absence of a catalyst, the conversion of cyclohexyl acetate was only $1.4 \%$ (Table 2, entry 1). The cyclohexyl acetate conversion over SAPIL-1, which presented high swelling ability in water $(\mathrm{Q}=24.5)$, was $81.9 \%$ (Table 2, entry 2). As the molar fraction of the $\left[\mathrm{EG}_{3}(\mathrm{VIm})_{2}\right] \mathrm{Br}_{2}$ crosslinker increased from $2.5 \%$ to $5 \%$ and $10 \%$, the swelling ability of SAPILs decreased from $Q=24.5$ to 14.3 and 6.5 , respectively; moreover, the cyclohexyl acetate conversion decreased from $81.9 \%$ to $70.0 \%$ and $62.9 \%$, respectively (Table 2, entries 3 and 4). This could be attributed to the low swelling ability of the SAPILs hindering the exposure of the acid sites and leading to the incomplete accessibility of the reactants to the acid sites. The $Q$ value and cyclohexyl acetate conversion ability of SAPIL-5, which was synthesized using [O(VIm) $\left.)_{2}\right] \mathrm{Br}_{2}$, a more hydrophobic crosslinker than $\left[\mathrm{EG}_{3}\left(\mathrm{Vim}_{2}\right] \mathrm{Br}_{2}\right.$, were 14.4 and $72.9 \%$ respectively (Table 2 , entry 5 ). In addition, the $Q$ value and cyclohexyl acetate conversion ability of SAPIL-6, which was synthesized using VSbIm, an IL monomer with a longer alkyl chain than VSIm, were 27.4 and $81.5 \%$, respectively (Table 2, entry 6). Typically, the catalytic activity of the SAPILs was approximately linearly correlated with their swelling ability in water (Fig. S11).

For comparison, heterogeneous acid catalysts Amberlite IR-120(H) and H-ZSM-5, and homogeneous acid catalysts $\mathrm{H}_{2} \mathrm{SO}_{4}$, [VSIm] $\mathrm{HSO}_{4}$, and $p$-TsOH were used to catalyze the hydrolysis of cyclohexane acetate to cyclohexanol. The catalytic activities of these catalysts were much lower than that of SAPIL-1 (Table 2, entries 7-11). Particularly, the cyclohexanol selectivity of H-ZSM-5 was only $36.3 \%$, which was much lower than those of the analyzed SAPILs (98.3\%-98.9\%). The low selectivity of H-ZSM-5 could be attributed to the multiple acid strengths of H-ZSM-5, as demonstrated by its ${ }^{31} \mathrm{P}$ solid-state MAS NMR spectrum (Fig. 2(c)). These results demonstrated that SAPILs with single acid strength presented advantages for improving the selectivity.

To further compare the efficiencies of various catalysts, cat- alytic kinetic investigations were performed and the results are presented in Fig. 5 and Table S5. The catalytic rate of SAPIL-1 was much higher than those of the other analyzed catalysts, and allowed the reaction to reach equilibrium after $7 \mathrm{~h}$. These results further indicated that SAPILs were superior to other acid catalysts for the hydrolysis of cyclohexyl acetate. The reaction rate of the process catalyzed by $\mathrm{H}-\mathrm{ZSM}-5$ was similar to those of the reactions catalyzed by $\mathrm{H}_{2} \mathrm{SO}_{4}$ and [VSIm] $\mathrm{HSO}_{4}$, but the selectivities of these three catalysts only ranged from $36.3 \%$ to $58.0 \%$, which were much lower than those of the other analyzed catalysts (Table S5).

In addition to their remarkable catalytic performance for the hydrolysis of cyclohexyl acetate, SAPILs also exhibited excellent catalytic activity for the hydrolysis of other esters. As presented in Fig. 6 and Table S6, the catalytic activity of SAPIL-1 was much higher than those of $p$-TsOH, $\mathrm{H}_{2} \mathrm{SO}_{4}$, [VSIm] $\mathrm{HSO}_{4}$, and Amberlite IR-120(H) for the hydrolysis of cyclohexyl propionate, cyclohexyl butyrate, and phenol acetate under the same reaction conditions. These results demonstrated that SAPILs were some of the best heterogeneous acid

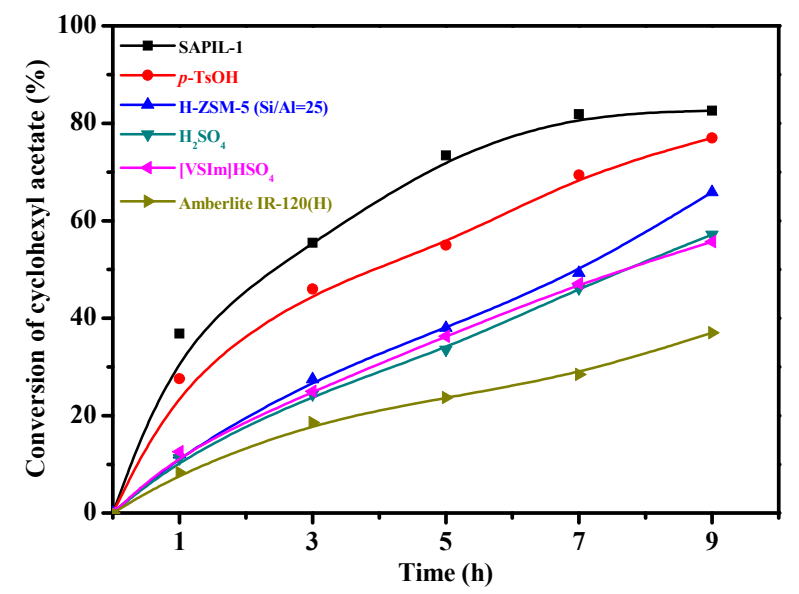

Fig. 5. Catalytic kinetics of various catalysts for the hydrolysis of cyclohexyl acetate. Reaction conditions: $10 \mathrm{mmol}$ cyclohexyl acetate, 250 mmol $\mathrm{H}_{2} \mathrm{O}, 0.4 \mathrm{mmol}$ catalyst, $100^{\circ} \mathrm{C}, 1$ bar $\mathrm{N}_{2}$. 


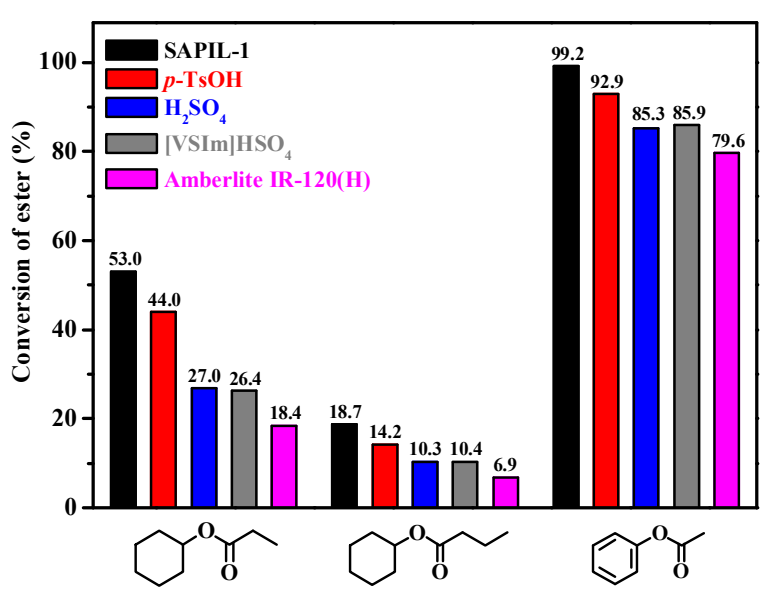

Fig. 6. Catalytic activity of various catalysts for the hydrolysis of cyclohexyl propionate, cyclohexyl butyrate, and phenyl acetate. Reaction conditions: $10 \mathrm{mmol}$ ester, $250 \mathrm{mmol} \mathrm{H}_{2} \mathrm{O}, 0.4 \mathrm{mmol}$ catalyst, $100{ }^{\circ} \mathrm{C}, 7$ h, 1 bar $\mathrm{N}_{2}$.

catalysts for the hydrolysis of esters.

Enrichment ability of SAPILs in swollen state. The catalytic activity of heterogeneous acid catalysts is typically much lower than that of homogeneous acid catalysts [17]. However, SAPILs exhibited much higher activities than homogeneous acid catalysts for the hydrolysis of esters. The excellent catalytic activity of SAPILs was attributed to their unique micron-sized 3D honeycomb structure and ester enrichment ability in swollen state.

To reveal the role of SAPILs during these catalytic processes, the equilibrium concentrations of each component of a series of simulated reaction mixtures (Mixture-10\%, 30\%, 50\%, 70\%, and $90 \%$ ) inside and outside of SAPIL-1 in aqueous phase were analyzed using GC, and the concentrations of cyclohexyl acetate, cyclohexanol, and acetic acid inside and outside SAPIL-1 were obtained (Table S7). The concentrations of acetic acid inside and outside SAPIL-1 were the same for all simulated reaction mixtures, which indicated that SAPIL-1 did not present enrichment ability for acetic acid. The concentrations of cyclohexanol inside SAPIL-1 were 1.3-2.6 times higher than those outside of SAPIL-1 (Figs. S12 and 13). However, the concentrations of cyclohexyl acetate inside SAPIL-1 were 7.5-23.3 times higher than those outside of SAPIL-1 (Figs. 7(a) and S13). For each simulated reaction mixture, the ratio of the cyclohexyl acetate concentrations inside and outside of SAPIL-1 was much higher than those of cyclohexanol and acetic acid (Fig. S13). These results suggested that cyclohexyl acetate could be highly concentrated by SAPIL-1 during the entire catalytic process. The high enrichment ability of SAPIL-1 for cyclohexyl acetate could be attributed to its unique chemical structure and micron-sized 3D honeycomb morphology it formed in water.

Furthermore, to analyze the enrichment ability of SAPIL-1 intuitively, the cyclohexyl acetate-to-cyclohexanol molar ratio inside and outside of SAPIL-1 were calculated. As presented in Fig. 7(b), the cyclohexyl acetate-to-cyclohexanol molar ratios inside SAPIL-1 were much higher than those outside of SAPIL-1 for the same simulated reaction mixtures. For example, for Mixture-50\%, the cyclohexyl acetate-to-cyclohexanol molar ratio inside SAPIL-1 was 0.332 , which was 5.2 times higher than that outside of SAPIL-1 (0.064). Therefore, these results also demonstrated the high enrichment of SAPIL-1 for cyclohexyl acetate.

For comparison, we analyzed the catalysis of the simulated reaction mixtures (Mixture-10\%, 30\%, 50\%, 70\%, and 90\%) in the presence of the homogeneous acid catalyst $p$ - $\mathrm{TsOH}$, and measured the concentrations of cyclohexyl acetate, cyclohexanol, and acetic acid in the aqueous phase. The concentrations of all components in the homogeneous system ( $p$-TsOH) were very similar to those outside of SAPIL-1 (Table S7). Thus, the concentrations of cyclohexyl acetate in the homogeneous system $(p-\mathrm{TsOH})$ were much lower than those inside SAPIL-1. These results indicated that the density of cyclohexyl acetate in the homogeneous system ( $p$-TsOH) was much lower than that inside SAPIL-1 during the hydrolysis process.

CA tests indicated that the CA of cyclohexyl acetate on SAPIL-1 $\left(21.3^{\circ}\right)$ was lower than that of cyclohexanol $\left(41.2^{\circ}\right)$ (Fig. 7(c)). These results indicated that the affinity of cyclohexyl acetate for SAPIL-1 was higher than that of cyclohexanol, which resulted in the enrichment of cyclohexyl acetate inside SAPIL-1. (a)

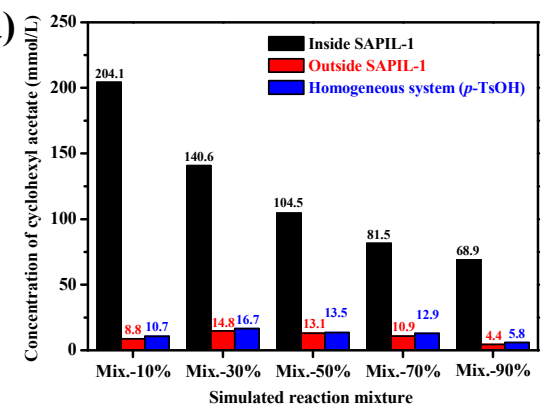

(b)

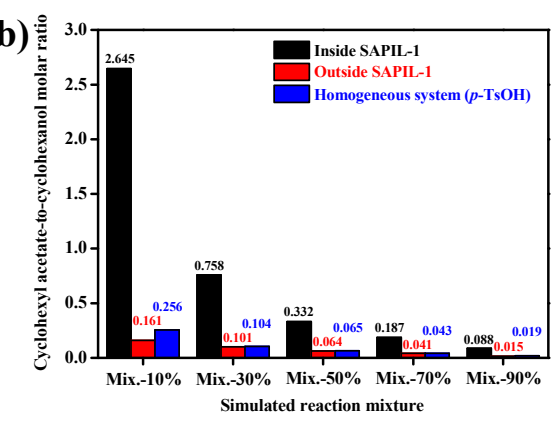

(c)

i)

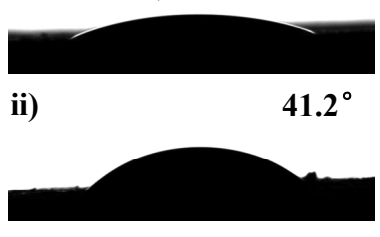

Fig. 7. (a) Concentration of cyclohexyl acetate in the aqueous phase of the simulated reaction mixtures. (b) Cyclohexyl acetate-to-cyclohexanol molar ratio in the aqueous phase of the simulated reaction mixtures. (c) Contact angles of (i) cyclohexyl acetate and (ii) cyclohexanol on the surface of SAPIL-1. Mixture-10\%: cyclohexyl acetate ( $9 \mathrm{mmol}), \mathrm{H}_{2} \mathrm{O}$ (249 mmol), cyclohexanol (1 mmol), acetic acid (1 mmol); Mixture-30\%: cyclohexyl acetate (7 mmol), $\mathrm{H}_{2} \mathrm{O}(247 \mathrm{mmol})$, cyclohexanol ( $\left.3 \mathrm{mmol}\right)$, acetic acid (3 mmol); Mixture-50\%: cyclohexyl acetate (5 mmol), $\mathrm{H}_{2} \mathrm{O}(245 \mathrm{mmol}), \mathrm{cyclohexanol}$ (5 mmol), acetic acid (5 mmol); Mixture-70\%: cyclohexyl acetate ( $3 \mathrm{mmol}), \mathrm{H}_{2} \mathrm{O}$ (243 mmol), cyclohexanol (7 mmol), acetic acid (7 mmol); Mixture-90\%: cyclohexyl acetate (1 mmol), $\mathrm{H}_{2} \mathrm{O}$ (241 mmol), cyclohexanol (9 mmol), acetic acid (9 mmol); SAPIL-1 (0.102 g, $\left.0.2 \mathrm{mmol}\right) ; p$-TsOH (0.038 g, $0.2 \mathrm{mmol})$. 
Consequently, during the hydrolysis of cyclohexyl acetate to cyclohexanol, the density of cyclohexyl acetate inside SAPIL-1, which presented micron-sized 3D honeycomb structure in water and high enrichment ability for cyclohexyl acetate, was high during the entire catalytic process (Fig. S14), and thus, it led to the great enhancement of the catalytic activity of SAPIL-1. Owing to their unique 3D honeycomb structure in water and the high enrichment ability for esters, SAPILs presented excellent catalytic activity for the hydrolysis of esters.

Reaction mechanism. Typically, acid-catalyzed reactions involve nucleophile substitution $\left(\mathrm{S}_{\mathrm{N}} 1\right.$ and $\left.\mathrm{S}_{\mathrm{N}} 2\right)$ or elimination (E1) reaction mechanisms [7,18,19,51-53]. In this study, the hydrolysis of cyclohexyl acetate was a typical nucleophile substitution reaction $\left(\mathrm{S}_{\mathrm{N}} 2\right.$ mechanism). The mechanism of the hydrolysis of cyclohexyl acetate over SAPILs is presented in Fig. S15. First, the carbonyl group of cyclohexyl acetate was protonated by the SAPIL catalyst, and thus, it became more electrophilic. Second, the protonated cyclohexyl acetate was subjected to the nucleophilic attack of the $\mathrm{O}$ atom of $\mathrm{H}_{2} \mathrm{O}$, which led to the formation of the intermediate. Third, cyclohexanol, the product, was obtained via the proton transfer from the intermediate. Lastly, the SAPIL catalyst was regenerated after the release of acetic acid.

Catalyst recycling. The reusability of the SAPILs was tested for the hydrolysis of cyclohexyl acetate under optimized reaction conditions. The SAPIL-1 catalyst was easily recovered via deswelling (Fig. S16), and presented remarkable reusability and stability after 10 cycles (Fig. 8). The conversion of cyclohexyl acetate and selectivity of cyclohexanol were maintained at approximately $80 \%$ and $98 \%$, respectively. In addition, the acid concentration $(1.91 \mathrm{mmol} / \mathrm{g})$ and swelling ability in water $(\mathrm{Q}=23.0)$ of SAPIL-1 were not changed after 10 cycles (Table S8). No significant differences were observed in the FT-IR spectra of SAPIL-1 before and after it was reused (Fig. S17). The superior reusability of the SAPILs was ascribed to their good thermal and chemical stability and reversible swelling-deswelling ability.

Direct hydration of cyclohexene to cyclohexanol. The catalytic performance of SAPILs was evaluated via the direct hydration of cyclohexene to cyclohexanol. Fig. 9 and Table S9 illustrate the catalytic activities of SAPIL- 1 and $p$-TsOH for the direct

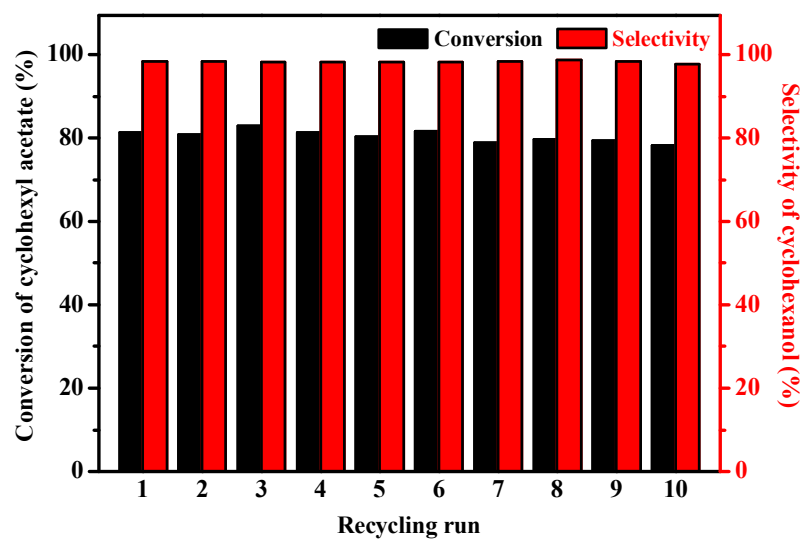

Fig. 8. Catalytic reusability of SAPIL-1 for the hydrolysis of cyclohexyl acetate.

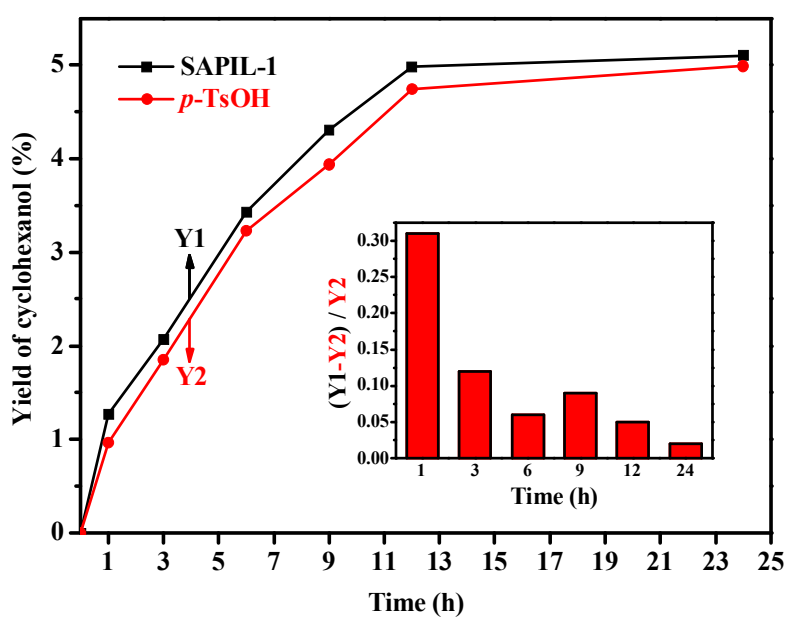

Fig. 9. Direct hydration of cyclohexene to cyclohexanol catalyzed by SAPIL-1 and $p$-TsOH. Reaction conditions: $20 \mathrm{mmol}$ cyclohexene, 200 $\mathrm{mmol} \mathrm{H}_{2} \mathrm{O}, 0.2 \mathrm{mmol}$ (1 mol\%) catalyst, $130^{\circ} \mathrm{C}, 0.5 \mathrm{MPa} \mathrm{N}_{2}, 1000 \mathrm{rpm}$.

hydration of cyclohexene under the same reaction conditions. The catalytic activity of SAPIL-1 was higher than that of the homogeneous acid catalyst $p$-TsOH. The cyclohexanol yields obtained over SAPIL-1 were $2 \%-31 \%$ higher than those obtained over $p$-TsOH (Fig. 9). These results indicated that SAPILs were highly efficient heterogeneous acid catalysts for the direct hydration of cyclohexene to cyclohexanol.

\subsubsection{Hydration of EO to $E G$}

EG is an important chemical raw material for the manufacture of polyester, antifreeze, lubricants, and other chemicals [54]. EG is most commonly synthesized via the catalytic hydration of EO. Various types of catalysts such as $\mathrm{H}_{2} \mathrm{SO}_{4}$, ion-exchange resins, metal oxides, and zeolites, have been used for the industrial hydration of EO to EG [55-57]. In this study, we used APILs as catalysts for the hydration of EO to EG for the first time. As presented in Fig. 10, the catalytic performance of SAPILs for the hydration of EO to EG was good, and was much

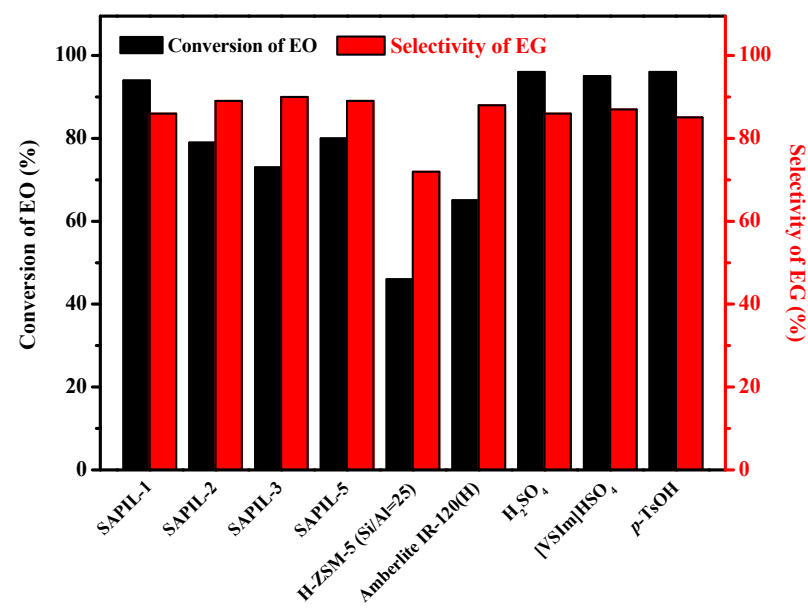

Fig. 10. Hydration of ethylene oxide (EO) to ethylene glycol (EG) over various catalysts. Optimized reaction conditions (see Table S10): 50 mmol EO, $500 \mathrm{mmol} \mathrm{H} 2 \mathrm{O}, 0.06 \mathrm{mmol}(0.12 \mathrm{~mol} \%)$ catalyst, $100{ }^{\circ} \mathrm{C}, 0.5 \mathrm{~h}$ 1.0 $\mathrm{MPa} \mathrm{N} \mathrm{N}_{2}$. 
better than that of the commercial resin Amberlite IR-120(H) and H-ZSM-5. The catalytic activity of SAPIL-1, which did not present enrichment ability for the EO (Fig. S18), for this reaction was comparable with those of homogeneous acid catalysts. That could be attributed to the high swelling ability of SAPIL-1 in water facilitating the exposure of the acid sites to the reactants [26]. Therefore, SAPILs were highly efficient heterogeneous acid catalysts for the hydration of EO to EG, and presented potential for future industrial applications.

\section{Conclusions}

SAPILs with moderate and single acid strength, adjustable acid concentration, and good stability were successfully synthesized via the free radical copolymerization of IL monomers, NaSS, and crosslinkers, followed by acidification. The synthesized SAPILs spontaneously self-assembled into micron-sized $3 \mathrm{D}$ honeycomb structures when swelling in water. The diameters of the honeycomb channels gradually increased from 3-6 to $20-30 \mu \mathrm{m}$ as the swelling ability of SAPILs in water increased from $Q=6.5$ to 24.5. SAPILs with honeycomb structure in water were used as highly efficient solid acid catalysts for hydrolysis and hydration reactions. The catalytic activity of the synthesized SAPILs was much higher than those of homogeneous acid catalysts, such as $\mathrm{H}_{2} \mathrm{SO}_{4}$, [VSIm] $\mathrm{HSO}_{4}$, and $p$-TsOH, for the hydrolysis of cyclohexyl acetate to cyclohexanol. The concentrations of cyclohexyl acetate and cyclohexyl acetate-to-cyclohexanol molar ratios inside SAPIL-1 for a series of simulated reaction mixtures were 7.5-23.3 and 4.5-16.4 times higher, respectively, than those outside of SAPIL-1, which indicated the high enrichment ability of SAPILs for cyclohexyl acetate. The excellent catalytic activity of the synthesized SAPILs was attributed to their micron-sized 3D honeycomb structure in water and high enrichment ability for the reactants. Moreover, the SAPILs presented outstanding catalytic activity for the hydration of cyclohexene and EO. The SAPILs were facilely recovered via deswelling, and displayed remarkable reusability after 10 cycles. These features of SAPILs could provide a new strategy for designing stable and highly efficient heterogeneous acid catalysts.

\section{Conflicts of interest}

There are no conflicts to declare.

\section{Appendix A. Supporting Information}

Syntheses of $\left[\mathrm{EG}_{3}(\mathrm{VIm})_{2}\right] \mathrm{Br}_{2},\left[\mathrm{O}(\mathrm{VIm})_{2}\right] \mathrm{Br}_{2}$ and $[\mathrm{VSIm}] \mathrm{HSO}_{4}$; NMR spectra; FT-IR spectra; XPS spectra; XRD pattern; swelling abilities of SAPILs and SAPIL precursors; cryo-SEM images; catalytic data for hydrolysis of esters; catalytic data for hydration of cyclohexene and ethylene oxide; details in enrichment ability; titration data; recycling process; reaction mechanism.

\section{References}

[1] A. Corma, H. García, Chem. Rev., 2003, 103, 4307-4365.

[2] S. Singhal, S. Agarwal, S. Arora, N. Singhal, A. Kumar, Catal. Sci. Technol., 2017, 7, 5810-5189.

[3] P. Sudarsanam, E. Peeters, E. V. Makshina, V. I. Parvulescu, B. F. Sels, Chem. Soc. Rev., 2019, 48, 2366-2421.

[4] F. Liu, K. Huang, A. Zheng, F-S. Xiao, S. Dai, ACS Catal., 2018, 8, 372-391.

[5] T. Okuhara, Chem. Rev., 2002, 102, 3641-3666.

[6] Q. Wu, F. Liu, X. Yi, Y. Zou, L. Jiang, Green Chem., 2018, 20, 1020-1030.

[7] M. Li, F. Wu, Y. Gu, Chin. J. Catal., 2019, 40, 1135-1140.

[8] H. Wang, X. Meng, G. Zhao, S. Zhang, Green Chem., 2017, 19, 1462-1489.

[9] W. Long, C. W. Jones, ACS Catal., 2011, 1, 674-681.

[10] F. Liu, W. Kong, C. Qi, L. Zhu, F-S. Xiao, ACS Catal., 2012, 2, 565-572.

[11] F. Chen, L. Shi, J. Yao, Y. Wang, D. Zhang, W. Zhu, Z. Liu, Catal. Sci. Technol., 2018, 8, 580-590.

[12] Y. Wang, D. Wang, M. Tan, B. Jiang, J. Zheng, N. Tsubaki, M. Wu, ACS Appl. Mater. Interfaces, 2015, 7, 26767-26775.

\section{Graphical Abstract}

Chin. J. Catal., 2021, 42: 297-309 doi: 10.1016/S1872-2067(20)63658-0

\section{Honeycomb-structured solid acid catalysts fabricated via the swelling-induced self-assembly of acidic poly(ionic liquid)s for highly efficient hydrolysis reactions}

Bihua Chen, Tong Ding, Xi Deng, Xin Wang, Dawei Zhang, Sanguan Ma, Yongya Zhang, Bing Ni, Guohua Gao*

East China Normal University, China; University of Cambridge, U.K.

The catalytic activity of SAPILs with micron-sized 3D honeycomb structure in water and high enrichment ability for the reactants of hydrolysis and hydration reactions was much higher than that of homogeneous acid catalysts.

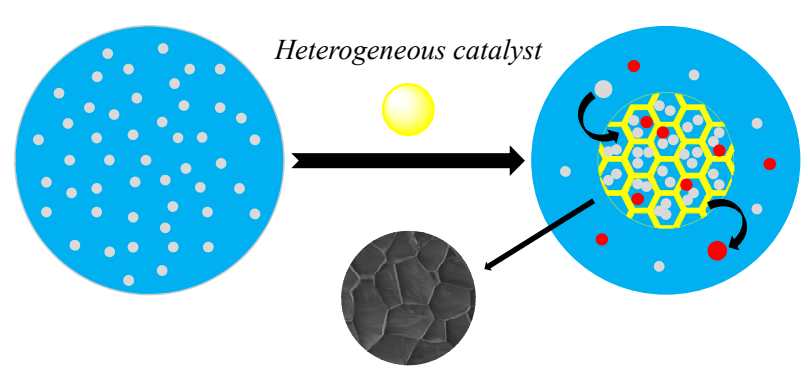

$=\mathrm{H}_{2} \mathrm{O}=$ Reactant $\mathrm{O}=$ Product $\mathrm{O}=$ SAPIL $8=$ Swollen SAPIL 
[13] G. Wang, H. Song, R. Li, Z. Li, J. Chen, Chin. J. Catal., 2018, 39, $1110-1120$.

[14] A. S. Amarasekara, Chem. Rev., 2016, 116, 6133-6183.

[15] W. Qian, J. Texter, F. Yan, Chem. Soc. Rev., 2017, 46, 1124-1159.

[16] J. Yuan, D. Mecerreyes, M. Antonietti, Prog. Polym. Sci., 2013, 38, 1009-1036.

[17] F. Liu, L. Wang, Q. Sun, L. Zhu, X. Meng, F-S. Xiao, J. Am. Chem. Soc., 2012, 134, 16948-16950.

[18] Y. Bian, J. Zhang, S. Zhang, C. Liu, D. Zhao, ACS Sustainable Chem. Eng., 2019, 7, 17220-17226.

[19] Z. Wu, C. Chen, Q. Guo, B. Li, Y. Que, L. Wang, H. Wan, G. Guan, Fuel, 2016, 184, 128-135.

[20] D-J. Tao, F. Liu, L. Wang, L. Jiang, Appl. Catal. A, 2018, 564, 56-63.

[21] J. Li, Y. Zhou, D. Mao, G. Chen, X. Wang, X. Yang, M. Wang, L. Peng, J. Wang, Chem. Eng. J., 2014, 254, 54-62.

[22] W. Hou, Q. Wang, Z. Guo, J. Li, Y. Zhou, J. Wang, Catal. Sci. Technol., 2017, 7, 1006-1016.

[23] Y. Feng, L. Li, X. Wang, J. Yang, T. Qiu, Energy Convers. Manage., 2017, 153, 649-658.

[24] J. Zhang, S. Zhang, J. Han, Y. Hu, R. Yan, Chem. Eng. J., 2015, 271, 269-275.

[25] A. Pourjavadi, S. H. Hosseini, M. Doulabi, S. M. Fakoorpoor, F. Seidi, ACS Catal., 2012, 2, 1259-1266.

[26] Y. Zhang, B. Wang, E. H. M. Elageed, L. Qin, B. Ni, X. Liu, G. Gao, ACS Macro Lett., 2016, 5, 435-438.

[27] Y. Zhang, Y. Zhang, B. Chen, L. Qin, G. Gao, ChemistrySelect, 2017, 2, 9443-9449.

[28] Y. Zhang, B. Chen, Y. Zhang, L. Qin, B. Liu, B. Ni, G. Gao, Green Chem., 2018, 20, 1594-1601.

[29] Y. Liu, W. Liu, L. Wang, M. Su, F. Liu, Ind. Eng. Chem. Res., 2018, 57, 5207-5214.

[30] T. Sommer, M. Zapletal, J. Trejbal, Chem. Pap., 2018, 72, 2397-2412.

[31] M. Kimura, T. Nakato, T. Okuhara, Appl. Catal. A, 1997, 165, 227-240.

[32] Q. Yang, M. P. Kapoor, N. Shirokura, M. Ohashi, S. Inagaki, J. N. Kondo, K. Domen, J. Mater. Chem., 2005, 15, 666-673.

[33] M. Hara, T. Yoshida, A. Takagaki, T. Takata, J. N. Kondo, S. Hayashi, K. Domen, Angew. Chem. Int. Ed., 2004, 43, 2955-2958.

[34] Q. Sun, S. Wang, X. Meng, B. Aguila, S. Ma, F-S. Xiao, Nat. Commun., 2018, 9, 3236.
[35] J. Zhang, S. Chen, B. Qin, D. Zhang, P. Guo, Q. He, Polymer, 2019, 164, 154-162.

[36] A. Zheng, S-B. Liu, F. Deng, Chem. Rev., 2017, 117, 12475-12531.

[37] A. Zheng, S-J. Huang, S-B. Liu, F. Deng, Phys. Chem. Chem. Phys., 2011, 13, 14889-14901.

[38] A. Zheng, S-J. Huang, Q. Wang, H. Zhang, F. Deng, S-B. Liu, Chin. J. Catal., 2013, 34, 436-491.

[39] T. Ono, T. Sugimoto, S. Shinkai, K. Sada, Nat. Mater., 2007, 6, 429-433.

[40] J. Chen, S. Wang, J. Peng, J. Li, M. Zhai, ACS Appl. Mater. Interfaces, 2014, 6, 14894-14902.

[41] H. Tokuda, K. Hayamizu, K. Ishii, M. A. B. H. Susan, M. Watanabe, J. Phys. Chem. B, 2005, 109, 6103-6110.

[42] W-F. Lee, G-H. Lin, J. Appl. Polym. Sci., 2001, 79, 1665-1674.

[43] T. Ono, T. Sugimoto, S. Shinkai, K. Sada, Adv. Funct. Mater., 2008, 18, 3936-3940.

[44] G. Yan, J. Yu, Y. Qiu, X. Yi, J. Lu, X. Zhou, X. Bai, Langmuir, 2011, 27, 4285-4289.

[45] V. D. Deepak, S. K. Asha, J. Phys. Chem. B, 2006, 110, 21450-21459.

[46] Q-L. Zhu, W. Xia, T. Akita, R. Zou, Q. Xu, Adv. Mater., 2016, 28, 6391-6398.

[47] Y. Xu, T. Wang, Z. He, M. Zhou, W. Yu, B. Shi, K. Huang, Macromolecules, 2017, 50, 9626-9635.

[48] B. Wang, S. Li, X. Wu, J. Liu, J. Chen, J. Mater. Chem. A, 2016, 4 , 11789-11799.

[49] Y. Li, Y. Zhou, C. Zhu, Y. H. Hu, S. Gao, Q. Liu, X. Cheng, L. Zhang, J. Yang, Y. Lin, Catal. Sci. Technol., 2018, 8, 5325-5333.

[50] H. Wang, K. Sun, F. Tao, D. J. Stacchiola, Y. H. Hu, Angew. Chem. Int. Ed., 2013, 52, 9210-9214.

[51] A. Taheri, C. Liu, B. Lai, C. Cheng, X. Pan, Y. Gu, Green Chem., 2014, $16,3715-3719$.

[52] A. Taheri, X. Pan, C. Liu, Y. Gu, ChemSusChem, 2014, 7, 2094-2100.

[53] A. El-Harairy, Yiliqi, B. Lai, L. Vaccaro, M. Li, Y. Gu, Adv. Synth. Catal., 2019, 361, 3342-3350.

[54] H. Yue, Y. Zhao, X. Ma, J. Gong, Chem. Soc. Rev., 2012, 41, 4218-4244.

[55] D. F. Othmer, M. S. Thakar, Ind. Eng. Chem., 1958, 50, 1235-1244.

[56] L. M. Reed, L. A. Wenzel, J. B. O'Hara, Ind. Eng. Chem., 1956, 48, 205-208.

[57] Y. Li, B. Yue, S. Yan, W. Yang, Z. Xie, Q. Chen, H. He, Catal. Lett., 2004, 95, 163-166.

\title{
酸性聚离子液体溶胀诱导自组装形成类蜂窝状固体酸催化剂及其 高效催化水解反应
}

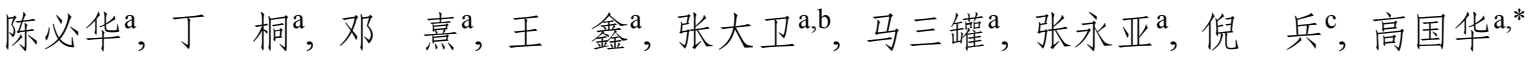 \\ a华东师范大学化学与分子工程学院, 上海市绿色化学与化工过程绿色化重点实验室, 上海200062, 中国 \\ b剑桥大学化学系, 剑桥 CB2 1EW, 英国 \\ c华东师范大学生命科学学院, 上海200241, 中国
}

摘要: 酸催化反应在化学工业中占据着十分重要的地位. 传统的液体酸催化剂催化性能优异, 但面临着能耗高, 腐蚀设备 和环境污染严重等问题. 相比于传统的液体酸催化剂, 固体酸催化剂, 如分子篮和磺酸树脂等大大缓解了经济和环境方面 的问题, 但也存在着催化活性差和易失活等缺陷. 酸性聚离子液体因其高密度的反应活性位点, 可设计调变的结构和酸性 以及可循环利用等特性而成为一种新型的高效多相酸催化剂, 引起了广泛的研究兴趣. 然而, 当酸性聚离子液体用作催化 剂时, 由于其酸中心不能充分地暴露在反应底物中, 使得它们的催化活性难以达到甚至超越均相催化剂的水平. 因此, 发 展一种催化活性高于均相的酸性聚离子液体催化剂仍是一个巨大的挑战. 我们研究组发现在反应底物中溶胀的聚离子液 体可作为一种准均相催化剂, 其催化活性与相应的均相离子液体相当, 这为提高多相催化剂的催化活性提供了一种新的策 
略.

本文报道了一种在水中溶胀且自组装成类蜂窝状网络结构的酸性聚离子液体催化剂, 该催化剂在水解和水合反应中 表现出优异的催化性能, 其活性高于均相酸催化剂. 首先通过自由基聚合和酸化两步合成了一系列在水中高度溶胀的酸 性聚离子液体(SAPIL-1-6). 以三甲基磷氧(TMPO)为探针分子, 用 ${ }^{31} \mathrm{P}$ 魔角旋转核磁共振 ( ${ }^{31} \mathrm{P}-\mathrm{TMPO}$ NMR)对SAPILs的酸性 进行了分析. 结果表明, SAPILs具有中等强度的单一酸性. 热重分析表明SAPILs拥有优异的热稳定性能 $\left(300-345^{\circ} \mathrm{C}\right)$, 显 著地优于商用磺酸树脂Amberlite IR-120(H) $\left(245^{\circ} \mathrm{C}\right)$. 扫描电镜和冷冻电镜表明, 当SAPILs在水中溶胀时, 无孔的结构会自 发地形成微米级三维类蜂窝状网络结构. 这些类蜂窝状网络结构的酸性聚离子液体在催化乙酸环己酯水解制备环己醇中 表现出卓越的催化性能, 其催化活性明显高于多相酸催化剂(Amberlite IR-120(H)和H-ZSM-5)和均相酸催化剂(硫酸, 对甲 苯磺酸和均相酸性离子液体 $\left[\right.$ VSIm] $\left.\mathrm{HSO}_{4}\right)$. 通过气相色谱定量分析了在一系列模拟的反应体系中溶胀SAPIL-1内部和外部 各组分的平衡浓度, 发现SAPIL-1 内部乙酸环己酯的浓度和乙酸环己酯与环己醇的摩尔比分别是其外部的7.5-23.3倍和 4.5-16.4倍, 这表明在反应过程中乙酸环己酯被大量富集. 此外, SAPILs在环己烯直接水合制备环己醇以及环氧乙烷水合 制备乙二醇的反应中均表现出优异的催化性能. 值得说明的是, SAPILs具有很好的循环使用性能, 10次循环后催化活性无 明显改变. 这些具有蜂窝状结构和对反应底物高富集SAPILs的成功合成及应用为开发高效的多相酸催化剂提供了一种新 的思路.

关键词: 多相酸催化剂; 酸性聚离子液体; 溶胀; 三维类蜂窝状网络结构; 富集; 水解; 水合

收稿日期: 2020-03-29. 接受日期: 2020-05-08. 出版日期: 2021-02-05.

*通讯联系人. 电话/传真: (021)62233323; 电子信箱: ghgao@chem.ecnu.edu.cn

基金来源：国家自然科学基金(21773068, 21573072, 21811530273); 国家重点研发计划(2017YFA0403102); 上海市重点学科建设 项目(B409).

本文的电子版全文由Elsevier出版社在ScienceDirect上出版(http://www.sciencedirect.com/science/journal/18722067). 